\title{
A Histopathological Study on Gentamycin Induced Nephrotoxicity in Experimental Albino Rats
}

\author{
M.Pramila Padmini ${ }^{1}$, J. Vijay Kumar ${ }^{2}$ \\ ${ }^{1}$ (Assistant Professor of Anatomy, MIMS Medical College Vizianagaram, Nellimarla, India) \\ ${ }^{2}$ Professor of Anatomy, Saveetha Medical College, Chennai, India)
}

\begin{abstract}
Drug-induced nephrotoxicity is an important cause of renal failure. Aminoglycosides throughout the endocytic pathway are taken up into the epithelial cells of the renal proximal tubules and stay there for a long time, which leads to nephrotoxicity. Wistar-albino male rats weighing 125-150gms, are utilized for the present study.Blood samples were collected with cardiac puncture for biochemical investigations like blood urea, uric acid, creatinine, serum $\mathrm{Na}, \mathrm{K}, \mathrm{Ca}$, determination.By using one way ANOVA the results are significant at .001.Tubular epithelial necrosis and dilatation is observed effecting less than half of cortical tubules when rats treated with $60 \mathrm{mg} / \mathrm{kg}$ b.w.Hyaline cast formation is observed in PCT with atrophic glomeruli effecting half of the cortical regionwhen rats treated with $80 \mathrm{mg} / \mathrm{kg}$ b.w.gentamicin must be given in the lowest effective therapeutic doses in patients with normal kidney function.
\end{abstract}

Key words: gentamycin, glomeruli, hyaline cast, proximal convoluted tubules, urea

\section{Introduction}

Drug-induced nephrotoxicity is an important cause of renal failure. Aminoglycosides throughout the endocytic pathway are taken up into the epithelial cells of the renal proximal tubules and stay there for a long time, which leads to nephrotoxicity. Acidic phospholipids, broadly distributed in the plasma membranes in various tissues, were considered to be the binding site of aminoglycosides in brush-border membrane of proximal tubular cells (Nagai and Takano, 2004[1]; Nagai, 2006[2]). Hydroxyl radicals play a role in the pathogenesis of gentamicin nephrotoxicity, gentamicin can induce suppression of $\mathrm{Na}(+)-\mathrm{K}(+)$-ATPase activity and DNA synthesis in rats proximal tubules leading to renal injury; this injury may be relevant to reactive oxygen metabolites generated by gentamicin. Renal cortical mitochondria is the source of reactive oxygen metabolites, which induces renal injury( Nephrol Dial Transplant. 1994;9 Suppl 4:135-40[3]).

Very few studies of histopathology were reported in literature regarding histopathology of gentamicin induced renal failure in Albino rats. So, the present study is taken up to record the nephrotoxicity by biochemical investigation and histopathological damage in the structure of rat kidney.

\section{Materials And Methods}

Wistar - albino male rats weighing 125-150gms, are utilized for the present study. Experiments were performed with the permission of the institutional ethics committee.

In the present study, male albino rats were used and are grouped as follows:

○ I. controls with normal saline (groupI-6rats) for 10 days

- II.gentamicin $60 \mathrm{mg} / \mathrm{kg}$ b.w (groupII-6 rats) for 10 days

○ III.gentamicin $80 \mathrm{mg} / \mathrm{kg}$ b.w. (groupIII-6 rats) for 10 days

All rats were kept under observation for 1 week prior to the experiments to permit the animals to adjust to the environment. All animals were fed standard rat chow and were provided tap water to drink ad libitum. They were housed in a facility with $12-12 \mathrm{~h}$ light-dark cycle that is maintained at $25^{\circ} \mathrm{C}$. All animals were weighed before the injections. The animals were anaesthetized with ether inhalation. Blood samples were collected with cardiac puncture for biochemical investigations like blood urea, uric acid, creatinine, serum $\mathrm{Na}$, $\mathrm{K}, \mathrm{Ca}$, determination. Bilateral periumbilical vertical incisions were made. Right and left kidneys were removed quickly and weighed and preserved in $10 \%$ formalin.

2.1.Blood sampling:- At the end of each experimental period (10 days ) and after overnight fasting, animals were given high dose of chloroform. Blood samples were collected by cardiac puncture and animals are decapitated. Blood samples are centrifuged for 10 minutes at $3000 \mathrm{rpm}$ within an hour and the sera was obtained. All specimens of sera were stored at $-20^{\circ} \mathrm{C}$ until use.

2.2.Determination of serum urea, creatinine and uric acid:-The serum parameters were analyzed spectrophoto -metrically by using double beam UV Visible spectro-photometer (UV-Visible spectrophotometer, 
Elico, model SL 150). Estimation of blood urea, and creatinine were carried out using respective diagnostic kits purchased from Transasia Bio-medicals Ltd (HP) in collaboration with Erba diagnostics Mannheim GmbH (Germany) according to the methods of Talke and Schubert et al (1965[4]), Tiffany et al(1972[5]) respectively. Estimation of serum sodium and potassium was done by using Excel diagnostic kit method .

2.3.Determination of serum electrolytes:-Sodium $(\mathrm{Na})$ and Potassium $(\mathrm{K})$ analysis were accomplished by Excel diagnostic kit method according to the method of (Terri A.E et al 1958[6]). Serum calcium was determined colorimetrically using commercial kits (Erba, Germany) according to the method of Moorehead W $\mathrm{R}$ et al 1974[7].

2.4.Histopathological examination: Kidneys from first three groups were fixed in $10 \%$ neutral buffered formalin and processed to paraffin wax. 5 microns Sections are stained with Haematoxyllin and Eosin , Massons trichrome, and Periodic Acid Schiff and are examined under light microscope at 100 and 400 magnification.

\section{Results}

The values obtained are very much significant as shown in Table 1 .

Table (1): Nephrotoxic effects of gentamicin on some biochemical parameters in rats when compared to controls.

\begin{tabular}{|l|c|l|l|}
\hline & $\begin{array}{l}\text { Control } \\
\text { G I=6 rats }\end{array}$ & $\begin{array}{l}\text { gentamicin } \\
\text { 60mg/kgb.w } \\
\text { GII=6 rats }\end{array}$ & $\begin{array}{l}\text { gentamicin } \\
\text { 80mg/kgb.w } \\
\text { GIII=6 rats }\end{array}$ \\
\hline Body weight & $125-150 \mathrm{mg}$ & $115 \mathrm{mg}$ & $115 \mathrm{mg}$ \\
\hline PARAMETERS & MEAN+SD & MEAN+SD & MEAN+SD \\
\hline Urea $(\mathrm{mg} / \mathrm{dl})$ & $16.8+.6$ & $60.28+2.3$ & $74.18+2.03$ \\
\hline Creatinine $(\mathrm{mg} / \mathrm{dl})$ & $.48+.02$ & $1.82+.09$ & $2.15+.30$ \\
\hline Uric acid $(\mathrm{mg} / \mathrm{dl})$ & $.36+.06$ & $.81+.10$ & $1.05+.16$ \\
\hline Na $(\mathrm{meq} / \mathrm{L})$ & $125.63+2.14$ & $121.24+.97$ & $118.67+2.14$ \\
\hline $\mathrm{K}(\mathrm{meq} / \mathrm{L})$ & $4.11+.09$ & $4.83+.31$ & $5.51+.17$ \\
\hline $\begin{array}{l}\text { Total calcium } \\
\text { (mg/dl) }\end{array}$ & $9.31+.56$ & $8.76+.29$ & $7.55+.50$ \\
\hline
\end{tabular}

Mean, Standard deviation and one way ANOVA was done to know the significance. Values are expressed as means \pm S.D. By using one way ANOVA the results are significant at .001

\subsection{Histopathological Observations}

\subsubsection{Group-I treated with normal saline}

Male albino rats with intake of normal saline showed normal architecture of renal glomeruli with intact bowmans capsule(fig.1) Brush bordered cuboidal epithelium lining the proximal convoluted tubules(fig.2) Simple cuboidal epithelium lining the distal convoluted tubules .macula densa is very prominent(fig. $3 \mathrm{H} \& \mathrm{E}$, fig.4 Massons Trichrome ).

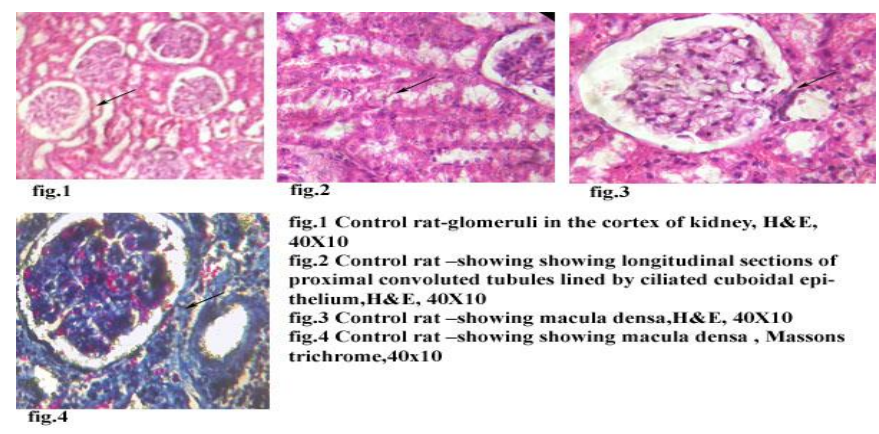

\subsubsection{Group-II - rats treated with $60 \mathrm{mg} / \mathrm{kg}$ b.w}

Epithelial cell degeneration and granular deposits in tubular lumens with evidence of tubular epithelial cell desquamation and lymphocytic infiltration around PCT (fig.5) Tubular epithelial necrosis and dilatation is observed effecting less than half of cortical tubules under 100 magnification (fig.6). 


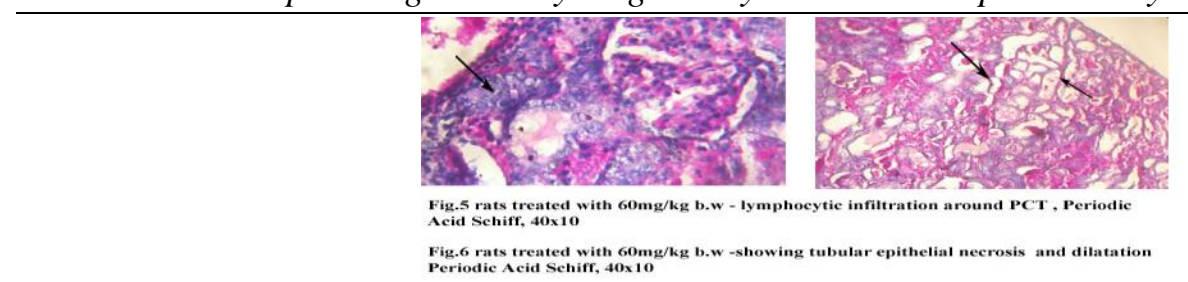

\subsubsection{Group-III -rats treated with $80 \mathrm{mg} / \mathrm{kg}$ b.w}

Close examination of these sections at high magnification, revealed the appearance of cells with alterations typical of apoptosis (cell shrinkage and cytoplasm eosinophilia and presence of a small and shrunken nucleus with chromatin condensation (fig.7). Break down of glomerular capillaries and vacuolar appearance in tubular lumen is observed(fig.8). The use of the periodic acid-Schiff reaction confirmed that these apoptotic cells were almost exclusively found in proximal tubules causing obstruction of PCT ' $\mathrm{S}$ (fig.9). Tubular basement membrane is interrupted. Glomerular congestion, disruption of glomerular capillaries, vacuolar degeneration of tubular epithelial cells is observed with hyaline cast formation is observed in PCT(fig.10). Atrophic glomeruli are present effecting half of the cortical region. Lymphocytic infiltration has increased (fig.11).

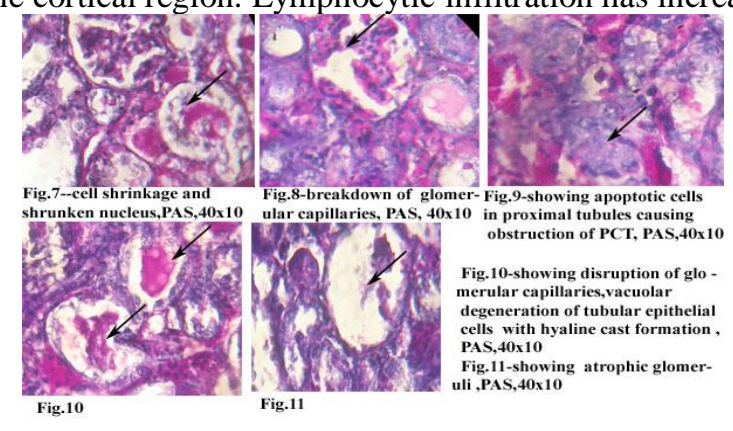

\section{Discussion}

The incidence of renal dysfunction following amino-glycoside administrationwas detected by many workers (Garetz and Schacht1996[8]; Baliga et al., 1997[9] and Abdel Naim etal.,1999[10]). Gentamicin is aminoglycoside broadspectrum antibiotic used against pathogenic gramnegative and positive bacteria (Taha, 1993[11]). Its administration into rats induced impairment of renal function through liberation of oxygen free radical (Heibashy \& Abdel Moneim, 1999 [12] and Heibashy et al.,2009[13]). Acute renal failure is characterized by disorders in some biochemical parameters in gentamicin treated rats as shown in the first experiment presented in Table -1. Rats treated with $60 \mathrm{mg} / \mathrm{kg}$ b.w and $80 \mathrm{mg} / \mathrm{kg}$ b.w. Gentamicin produced increase in the concentration of serum urea, creatinine and uric acid.

These results confirmed that gentamicin produced nephrotoxicity as previously reported by Ali et al., 2003[14], Goto, 2004 [15] and Heibashy et al.,2009[13]. These changes reflected the severity of renal insufficiency which occurred in association with the sudden fall in glomerular filtration rate because of the majority of administrated GM enters specifically the proximal tubular epithelial cells, binds to anionic phospholipids in the target cells inducing abnormalities in the function and metabolism of multiple intracellular membranes and organelles then developed injury in the proximal tubular epithelial cells of kidney that caused acute renal failure (Swan, 1997[16]). More than half of proximal tubules showing desquamation of necrosis but involved tubules easily found, complete or almost complete tubular necrosis. Serum electrolytes were disturbed in GM treated rats as compared with control animals.

Lower value of serum sodium indicated inability of kidney to conserve sodium and chloride. Haemodilution too may be involved in the fall of sodium value via excess of water intake and or increased production of endogenous water. Increase of Potassium may be due to reduced excretion of $\mathrm{K}$ aggravated by leakage of intracellular potassium into blood stream as a result of gentamicin induced lesions in renal tubular epithelium. The present results are in harmony with the data obtained by Heibashy \& Abdel Moneim (1999)[12] and Heibashy et al. (2009)[13]. Apoptosis plays a major role in kidney embryogenesis, resulting in large-scale cell death during development (Coles H S R et al 1993[17]). By contrast, in the adult and under normal circumstances, evidence of apoptosis is seldom found in the kidney, where the rate of cell turnover is very low. However, there are a number of documented cases related to kidney insult in both pathology and toxicology where the renal tissue, in particular the tubular epithelium, exhibits a substantial increase of apoptotic cells (Conaldi P G et al 1998[18], Davis M A et al 1998[19]).

Thus, apoptosis is clearly involved in ischemic renal atrophy (Gobe G C et al 1987[20]) Gentamicin treated rats show tubular eptithelial damage with intense granular degeneration involving $>50 \%$ of renal cortex. Some of the tubular epithelium contains tubular casts.as observed by K.Vijay Kumar et al 2000[21]) 
Renal tissue specimens obtained 30minutes after the 8th day of administration were examined histologically by Yoshiyama et al 1992 [22] with similar findings as observed by other authors.

Rats given GM in midlight (1:00pm) showed: tubular necrosis, degeneration, dilation together with regeneration of proximal tublar cells, cell infiltration in interstitium, and hyaline cast formation in the tubular lumen.(Yoshiyama et al 1992[22]). Gentamicin renal cell damage as induced by tubular necrosis ie, marked congestion of the glomeruli with glomerular atrophy, degeneration of tubular epithelial cells with casts in the tubular lumen and infiltration of inflammatory cells in the interstitium was confirmed on histopathological examination by Shirwaikar A et al 2003[23].

In the present study also shrunken glomeruli and glomerular atrophy is observed.

\section{Conclusion}

Daily intraperitonial injection of rats with $80 \mathrm{mg}$ gentamicin $/ \mathrm{kg}$ b.w for 10 days causes serious harmful effects and is evident on renal function tests. Thus, it could be suggested that gentamicin must be given in the lowest effective therapeutic doses in patients with normal kidney function. Also, gentamicin therapy should be preceded by antioxidant administration and renal function tests must be done to detect any early functional alterations.

\section{Acknowledgements}

I thank Dr.B.Narasinga Rao, Professor and HOD of Anatomy, Dr.T.A.V.Narayana Raju Dean, and Department of Pharmacology of Maharajahs Institute Of Medical Sciences and Dr. Saraswathi Professor and HOD of Anatomy, Saveetha Medical College for their encouragement and support.

Note: This study is a partial work of my Ph.D research, titled "An experimental anatomical study on the effectiveness of punarnava (Boerhaevia diffusa) on gentamycin induced renal failure in albino rat and to estimate the drug induced damage and revival of renal tissue"

[1] 1.Nagai J ,Takano M.,. Molecular aspects of renal handling of aminoglycosides and strategies for preventing the nephrotoxicity. Drug Metab Pharmacokinet (2004)19(3), 159-70.

[2] 2.Nagai J., Molecular mechanisms underlying renal accumulation of aminoglycoside antibiotics and mechanism-based approach for developing nonnephrotoxic aminoglycoside therapy. Yakugaku Zasshi(2006) 126(5), 327-35

3.Nephrol Dial Transplant. (1994) ;9 Suppl 4:135-40

4.Talke and Schubert, G.E Klin Wochschr (1965), 19, 43:174

5.Tiffany, T.O Jansen, J., Burtis C .A Overton J.B and Scott C. D. Clinical Chemistry (1972), 18: 829

6.Terri A.E and Sesin P.G, A.M.G. Clinical Pathology (1958),29, 86-89,

[7] 7.Moorehead W R and Briggs H.C Clinical chemistry, (1974), 20, 1458,
[8] 8.Garetz, S.L. and Schacht, J. "Ototoxicty of mice and men" In Handbook of auditory research, ed. By R.R. Fay and A.N. Popper, Vol. VII : Clinical aspect of hearing, ed. By T.R. Van De Water, A. N. Popper and R.R. Fay, PP. 116-154, Springer New York(1996).

[9] 9.Baliga, R.; Ueda, N.; Walker, P.D. and Shah, S.V. Oxidant mechanisms in toxic acute renal failure Am.J.Kidney.Dis., (1997), 29:465-477.

[10] 10.Abdel-Naim, A. B.; Abdel-Wahab, M. H. and Attia, F. F.:"Protective effects of vitamin e and probucol against Gentamicin nephrotoxicity in rats." Pharmacol Res., (1999),40 (2): 183-187.

[11] 11.Taha, A.M.: Effect of gentamicin on the histo pathology, histochemistry and biochemistry of kidney of albino rats. The New Egypt. J. Med., (1993), 8(4):956-961.

[12] 12.Heibashy, M. I. A. and Abdel Moneim, A. E.: Kidney and liver function tests after late Dimethyl sulfoxide (DMSO) administration in rats with gentamicin induced acute renal failure. J. Egypt. Ger. Soc. Zool., (1999), 30(A): 35-48.

[13] 13.Heibashy, M.I.A.; El-Nahla, A.M.; Ibrahim, A.I. and Saleh, Sh.Y.A. : Comparative study between dimethyl sulfoxide (DMSO),allopurinol and urate oxidase administration in nephrotoxic rats induced with gentamicin. 43rd Annual Veterinary Medical Symposium, College of Veterinary Medicine Nursing and Allied Health, Tuskegee University, Alabama, USA, (2009)

[14] 14.Ali,B.H.; Al-Qarawi, A.A.; Haroun,E.M. and Mousa, H.M.: The effect of treatment with gum arabic on gentamicin nephrotoxicity in rats Ren Fail., (2003), 25(1):15-20.

[15] 15.Goto, A.M.: "The role of lipid coronary heart disease" Kalamazoo, M. I. Upjhion Company. (2004)

[16] 16.Swan, S. K.: Aminoglycoside nephrotoxicity: review. Seminars in nephrology(1997), 17(1):27-33.

[17] 17.Coles H S R, Burne J F, Raff M C. Large scale normal cell death in the developing rat kidney and its reduction by epidermal growth factor. Development. (1993);118:777-784. [PubMed]

[18] 18.Conaldi P G, Biancone L, Bottelli A, Wade-Evans A, Racusen L C, Boccellino M, Toniolo A. HIV-1 kills renal tubular epithelial cells in vitro by triggering an apoptotic pathway involving caspase activation and Fas upregulation. J Clin Investig. (1998);102:20412049. [PMC free article] [PubMed]

[19] 19.Davis M A, Ryan D H. Apoptosis in the kidney. Toxicol Pathol. (1998);26:810-825. [PubMed]

[20] 20.Gobe G C, Axelsen R A. Genesis of renal tubular atrophy in experimental hydronephrosis in the rat. Role of apoptosis. Lab Investig. (1987);56:273-282. [PubMed]

[21] 21.K.Vijay Kumar, M.U.R. Naidu, Anwar A. Shifow, K.S. Ratnakar Probucol protects against gentamicin-induced nephrotoxicity in rats. Indian journal of pharmacology (2000); 32: 108-113

[22] 22.Yoshiyama, Teruaki Kobayashi and Fumiya Tomonaga Chronotoxical Study Of Gentamicin Induced Nephrotoxicity In Rats Journal Of Antibiotics May (1992)

[23] 23.Shirwaikar A, Malini S, Kumari SCProtective effect of Pongamia pinnata flowers against cisplatin and gentamicin induced nephrotoxicity in rats Indian J Exp Biol. (2003) Jan;41(1):58-62. 